\title{
El Niño-Southern Oscillation in Tropical and Midlatitude Column Ozone
}

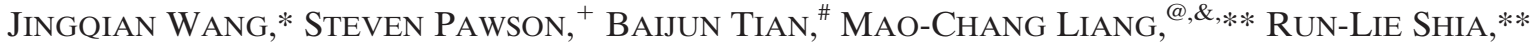 \\ YUK L. YUNG,** AND XUN JIANG* \\ * Department of Earth and Atmospheric Sciences, University of Houston, Houston, Texas \\ ${ }^{+}$Global Modeling and Assimilation Office, NASA GSFC, Greenbelt, Maryland \\ \# Jet Propulsion Laboratory, California Institute of Technology, Pasadena, California \\ ${ }^{\circledR}$ Research Center for Environmental Changes, Academia Sinica, Taipei, Taiwan \\ \& Graduate Institute of Astronomy, National Central University, Jhongli, Taiwan \\ ** Division of Geological and Planetary Sciences, California Institute of Technology, Pasadena, California
}

(Manuscript received 25 January 2011, in final form 4 April 2011)

\begin{abstract}
The impacts of El Niño-Southern Oscillation (ENSO) on the tropical total column ozone, the tropical tropopause pressure, and the 3.5-yr ozone signal in the midlatitude total column ozone were examined using the Goddard Earth Observing System Chemistry-Climate Model (GEOS CCM). Observed monthly mean sea surface temperature and sea ice between 1951 and 2004 were used as boundary conditions for the model. Since the model includes no solar cycle, quasi-biennial oscillation, or volcanic forcing, the ENSO signal was found to dominate the tropical total column ozone variability. Principal component analysis was applied to the detrended, deseasonalized, and low-pass filtered model outputs. The first mode of model total column ozone captured $63.8 \%$ of the total variance. The spatial pattern of this mode was similar to that in Total Ozone Mapping Spectrometer (TOMS) observations. There was also a clear ENSO signal in the tropical tropopause pressure in the GEOS CCM, which is related to the ENSO signal in the total column ozone. The regression coefficient between the model total column ozone and the model tropopause pressure was 0.71 Dobson units (DU) $\mathrm{hPa}^{-1}$. The GEOS CCM was also used to investigate a possible mechanism for the 3.5-yr signal observed in the midlatitude total column ozone. The 3.5-yr signal in the GEOS CCM column ozone is similar to that in the observations, which suggests that a model with realistic ENSO can reproduce the 3.5-yr signal. Hence, it is likely that the 3.5-yr signal was caused by ENSO.
\end{abstract}

\section{Introduction}

The influence of El Niño-Southern Oscillation (ENSO) on the sea surface temperature (SST), surface pressure, winds, and convection is well known (e.g., Trenberth and Shea 1987; Trenberth 1997). During El Niño events, temperature in the lower stratospheric is reduced in the tropics and increased in the Arctic (Garcia-Herrera et al. 2006; Free and Seidel 2009). Using a multiple regression method, Hood et al. (2010) found that ENSO can influence ozone volume mixing ratios. Ozone anomalies are negative in the lower stratosphere and positive in the middle stratosphere during El Niño (Hood et al. 2010). Chandra et al. (1998) and Thompson and Hudson (1999)

Corresponding author address: Jingqian Wang, Department of Earth and Atmospheric Sciences, University of Houston, Houston, TX 77204.

E-mail: jwang3@mail.uh.edu also identified an ENSO signal in the tropospheric column ozone: tropospheric column ozone decreases in the eastern Pacific and increases in the western Pacific as a result of the eastward shift of the tropical convective activity (Chandra et al. 1998). ENSO also affects the total column ozone abundance (Bojkov 1987; Shiotani 1992; Zerefos et al. 1992; Kayano 1997; Kita et al. 2000; Camp et al. 2003; Cagnazzo et al. 2009). Zerefos et al. (1992) found that ozone reductions in tropical regions could extend to middle and high latitudes following large El Niño events. Using the empirical orthogonal function (EOF) method, Kayano (1997) found that the first two modes of the total column ozone between $70^{\circ} \mathrm{N}$ and $70^{\circ} \mathrm{S}$ are related to ENSO. Kita et al. (2000) used total column ozone from the Total Ozone Mapping Spectrometer (TOMS) and found significant increase of total ozone over Indonesia during El Niño periods, which is related to the decreased precipitation and extensive forest fires occurring in the dry season during 
the El Niño periods. Camp et al. (2003) used the total column ozone observed by TOMS and revealed that there is an ENSO signal in the fourth mode of the total column ozone in the tropical region. The power spectral estimate of the principal component (PC) time series for the fourth mode reveals that most signals are related to the ENSO signal in total column ozone. There are negative total column ozone anomalies in the eastern tropical Pacific and positive total column ozone anomalies in the western Pacific during the El Niño events. The influence of ENSO on total column ozone can be explained by the variation in the tropopause height driven by changes of tropical deep convection and the changes of the BrewerDobson circulation (Schubert and Munteanu 1988; Shiotani 1992; Hasebe 1993; Garcia-Herrera et al. 2006; Free and Seidel 2009). Such a causal relationship between total column ozone and the tropopause height is also evident in the Madden-Julian oscillation (Tian et al. 2007). However, a quantitative demonstration of the impact of ENSO on total column ozone and tropopause height has not been carried out using model simulations to date.

In this paper, we will focus on the ENSO signal in the tropopause pressure and the total column ozone simulated by version 1 of the Goddard Earth Observing System Chemistry-Climate Model (GEOS CCM) (Pawson et al. 2008). Principal component analysis (PCA) will be applied to model total column ozone and the spatial pattern of the modeled ENSO signal will be compared with that from Camp et al. (2003). We will also investigate the mechanism for the 3.5-yr signal in midlatitude total column ozone. The 3.5-yr signal was first found in the total column ozone observations from Arosa, Switzerland, and the same signal also appears in the first leading mode of the Northern Hemispheric total column ozone (Jiang et al. 2008a). In this paper, we investigate a possible relationship between the 3.5-yr signal and ENSO.

\section{The GEOS chemistry-climate model and data}

The GEOS CCM (version 1) (Pawson et al. 2008) integrates the GEOS-4 general circulation model with a stratospheric chemistry model (Douglass et al. 2003; Stolarski et al. 2006). Atmospheric composition and dynamics are coupled through radiative heating. In the model radiation module, three-dimensional constituent concentrations $\left(\mathrm{CO}_{2}, \mathrm{O}_{3}, \mathrm{H}_{2} \mathrm{O}, \mathrm{CH}_{4}, \mathrm{~N}_{2} \mathrm{O}\right.$, CFC-11, and $\mathrm{CFC}-12$ ) vary as a function of time. The $\mathrm{P} 1$ model run of Pawson et al. (2008), to be analyzed in this study, spanned $54 \mathrm{yr}(1951-2004)$ at $2^{\circ}$ latitude $\times 2.5^{\circ}$ longitude with 55 layers between the surface and about $80 \mathrm{~km}$. Zonal-mean fields from this run were also included in Cagnazzo et al. (2009). At the lower boundary, monthly mean SST and sea ice were prescribed from observations (Rayner et al.
2003), along with time-dependent concentrations of greenhouse gases and chlorofluorocarbons (see Eyring et al. 2006). Neither the solar cycle nor volcanic aerosol variations was included in the model. This version of the model does not simulate a quasi-biennial oscillation (QBO) signal (see Horinouchi et al. 2003). The signals of these three sources of ozone variability are therefore all absent from the simulation.

To extract the ENSO signal in the GEOS CCM, two simulated monthly mean fields will be examined: the tropopause pressure $P_{T}$ and the total column ozone $\Omega_{S}$. The former field is obtained by using the lapse-rate definition tropopause (Sturman and Tapper 1996). The latter is the integrated profile of the total amount of ozone in the atmosphere. A comparative analysis of the imposed monthly mean SSTs between 1951 and 2004 will also be shown.

For comparison with the simulation, monthly mean total column ozone data from ground stations will be analyzed (data can be downloaded from http:// www.woudc.org/data_e.html). Twenty-one stations with continuous records longer than $20 \mathrm{yr}$ will be used in this paper, to include several complete cycles of the 3.5-yr ozone signal. Total column ozone time series from these stations will be compared with the model simulation.

\section{Methods}

The filtering and analysis technique of Jiang et al. (2008a,b) is applied to the GEOS CCM model outputs, which are the gridded monthly mean SST, $P_{T}$, and $\Omega_{S}$. The mean annual cycle and the linear trend computed for the 54-yr monthly time series were subtracted from the original time series to create the detrended monthly anomalies for each month. The mean annual cycle is calculated from the monthly mean fields for $54 \mathrm{yr}$ and the linear trend is calculated as linear regression of the 54-yr time series. A spectral filter was then applied to these monthly anomalies to separate the interannual variability (IAV) from higher-frequency oscillations. As in Jiang et al. (2008a,b), the filter was constructed to extract signals at periods longer than 15 months by convolving a step function with a Hanning window, which has a high concentration in the central lobe and insignificant side lobes.

These time-filtered anomalies of GEOS CCM SST, $P_{T}$, and $\Omega_{S}$ were used in a PCA (Preisendorfer 1988; Camp et al. 2003) to extract the leading spatial EOFs and their associated time-dependent amplitudes (the PC time series). PCA can reduce the dimensionality of the original dataset, and small sets of orthogonal functions are much easier to understand and analyze (Dunteman 1989). The EOFs are the orthogonal eigenfunctions of 
TABLE 1. Variances, spectral peaks, and correlations $(\mathrm{lag}=0)$ for the first modes of the GEOS CCM SST, $P_{T}$, and $\Omega_{\mathrm{S}}$.

\begin{tabular}{|c|c|c|c|c|c|}
\hline \multirow[b]{2}{*}{ Mode 1 of } & \multirow[b]{2}{*}{ Variance captured } & \multirow[b]{2}{*}{ Spectral peaks } & \multicolumn{3}{|c|}{ Correlations (significance level) with } \\
\hline & & & Low-pass-filtered SOI & SST (PC1) & $P_{T}(\mathrm{PC} 1)$ \\
\hline SST & $46.9 \%$ & 3.5 and $5 \mathrm{yr}$ & $0.88(0.1 \%)$ & - & - \\
\hline$P_{T}$ & $33.9 \%$ & 17 and 28 months, 3.5 and $5 \mathrm{yr}$ & $0.65(0.1 \%)$ & $0.72(0.1 \%)$ & - \\
\hline$\Omega_{S}$ & $63.8 \%$ & 17 and 28 months, $3.5 \mathrm{yr}$ & $0.53(0.1 \%)$ & $0.57(0.1 \%)$ & $0.82(0.1 \%)$ \\
\hline
\end{tabular}

the covariance matrix of the dataset sorted by the decreasing values of associated eigenvalues. Since these eigenvalues represent the variance captured by each EOF, PCA guarantees that the leading EOFs capture more of the total variance of the dataset than any other orthogonal vectors.

Observed total column ozone at different stations were deseasonalized and detrended before the power spectral analysis was applied. Spectral analysis was also applied to the model deseasonalized and detrended total column ozone. To obtain the statistical significance of signals in a power spectrum, the amplitudes of the spectral peaks were compared with a red noise spectrum (Gilman et al. 1963). The $10 \%$ and $5 \%$ significance levels for the power spectrum were found using $F$ statistics to compare the spectrum to the red noise spectrum.

\section{ENSO and 3.5-yr signals in total column ozone}

\section{a. ENSO signals}

ENSO is very important in the tropical region. To study variations of SST, $P_{T}$, and $\Omega_{S}$ in the tropical region $\left(25^{\circ} \mathrm{S}-25^{\circ} \mathrm{N}\right)$ during ENSO events, we use the PCA method to analyze the GEOS CCM results in the tropical region. The leading mode of the PCA of filtered tropical $\left(25^{\circ} \mathrm{S}-25^{\circ} \mathrm{N}\right)$ anomalies captures $46.9 \%, 33.9 \%$, and $63.8 \%$ of the total variance in GEOS CCM SST, $P_{T}$, and $\Omega_{S}$, respectively (Table 1 ). The Southern Oscillation index (SOI; the sea level pressure difference between Tahiti and Darwin) is used to calculate the correlations between ENSO and leading PC time series (the SOI is downloaded from http://www.cpc.noaa.gov/data/indices/ soi). For a fair comparison, we applied a low-pass filter to the detrended SOI index. Comparison of the time series of the detrended and low-pass filtered SOI and the amplitude of the first mode (PC1) of the SST (Fig. 1) reveals a good correlation, with in-phase variations. Note that negative (positive) SOI values denote the El Niño (La Niña) events. The correlation between the two time series is 0.88 and it is significant at the $0.1 \%$ level. The significance level was computed by a Monte Carlo method (Press et al. 1992): a small numerical value denotes high statistical significance. Time series of PC1 for
$P_{T}$ and $\Omega_{S}$ reveal a similar low-frequency oscillation as for low-pass filtered SOI, with some higher-frequency variations superimposed. This leads to somewhat lower correlations ( 0.65 and 0.53$)$ between these time series and the low-pass filtered SOI, but these remain highly significant (see Table 1). The correlation between PC1s of $P_{T}$ and $\Omega_{S}$ is 0.82 . The power spectra of the PC1s of SST, $P_{T}$, and $\Omega_{S}$ (Fig. 2) all show strong spectral peaks near 3$7 \mathrm{yr}$, similar to those in ENSO. The higher-frequency variations evident in $P_{T}$ and $\Omega_{S}$ also lead to prominent peaks near 17 months, which might be a beat frequency between the annual cycle and the ENSO signal.

Figure 3 shows the spatial patterns of the first mode of the PCA analysis for GEOS CCM SST, $P_{T}$, and $\Omega_{S}$, which describe their ENSO-related variability. For SST, the spatial pattern (Fig. 3a) is similar to the first mode of ENSO-related variability described in Trenberth et al. (2002, see their Fig. 11), which corresponds to the SST anomalies in the Niño-3.4 region (covering $5^{\circ} \mathrm{N}-5^{\circ} \mathrm{S}$, $\left.120^{\circ}-170^{\circ} \mathrm{W}\right)$. There are warm SST anomalies in the

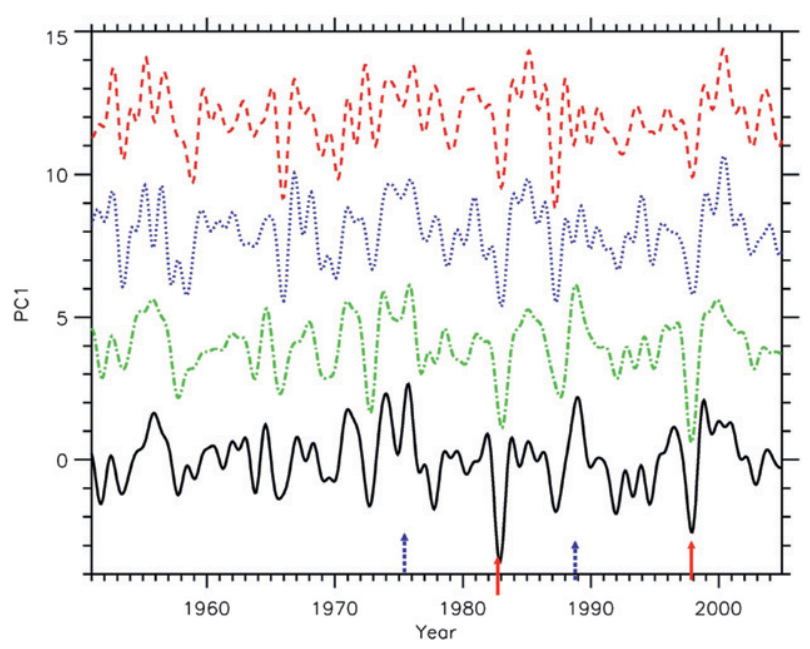

FIG. 1. PC1 time series for the first modes of the GEOS CCM SST (green dashed-dotted line, shifted upward by 4), $P_{T}$ (blue dotted line, shifted upward by 8 ), and $\Omega_{S}$ (red dashed line, shifted upward by 12). The low-pass filtered and detrended SOI index is shown by a black solid line. Red (blue) arrows represent El Niño (La Niña) events. Correlation coefficients between SOI and SST, $P_{T}$, and $\Omega_{S}$ are $0.88,0.65$, and 0.53 , respectively. 

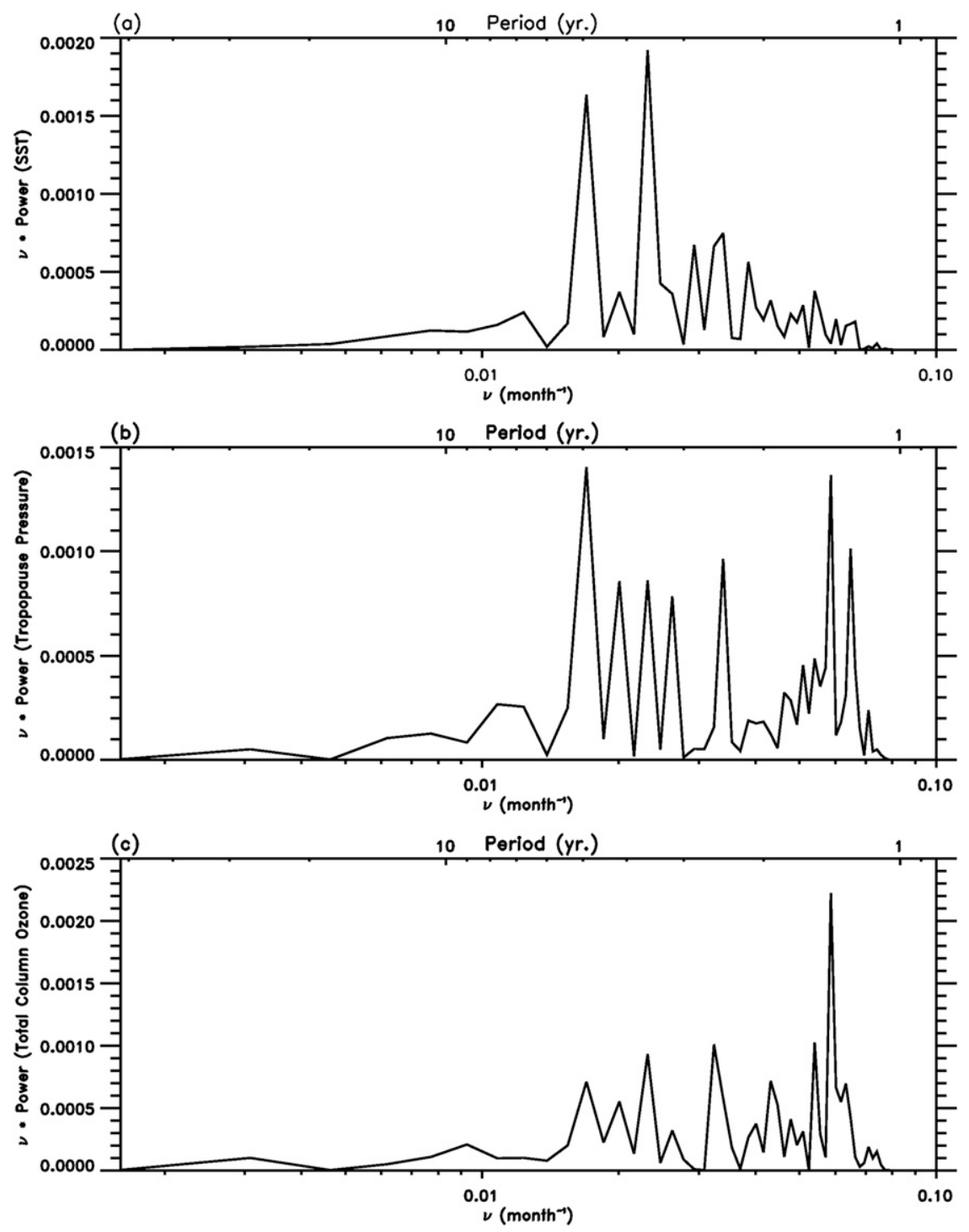

FIG. 2. Power spectra of PC1 for the first modes of GEOS CCM (a) SST, (b) $P_{T}$, and (c) $\Omega_{S}$.

central and western Pacific and a cold tongue in the eastern Pacific in the first mode of GEOS CCM SST. Negative amplitudes of this mode correspond to the El Niño events. During El Niño periods, the convection will move eastward to the central Pacific and impact the longitudinal structure of the tropopause (e.g., Gage and Reid 1987; Gettelman et al. 2001; Kiladis et al. 2001). The spatial pattern of the first mode of $P_{T}$ (Fig. 3b) is consistent with this behavior. For the negative amplitudes of this mode, corresponding to El Niño events, there are large negative tropopause pressure anomalies (higher tropopause height) in the central and eastern Pacific and weak positive tropopause pressure anomalies (lower tropopause heights) in the equatorial western Pacific. Note that the tropopause pressure anomalies are relatively small over the equatorial regions. On the other hand, large tropopause pressure anomalies are found over the subtropics, which is the Rossby wave response of the equatorial ENSO convection anomaly (Trenberth et al. 1998). In the positive amplitude of this mode, that is, during La Niña events, there are weak negative tropopause pressure anomalies (higher tropopause heights) in the equatorial western Pacific and large positive tropopause pressure anomalies (lower tropopause heights) in the central and eastern Pacific. The present results are in general agreement with previous studies on the tropopause pressure and height variability associated with ENSO based on reanalysis data (Kiladis et al. 2001; Gettelman et al. 2001). This indicates that the vertical movement of the tropopause 

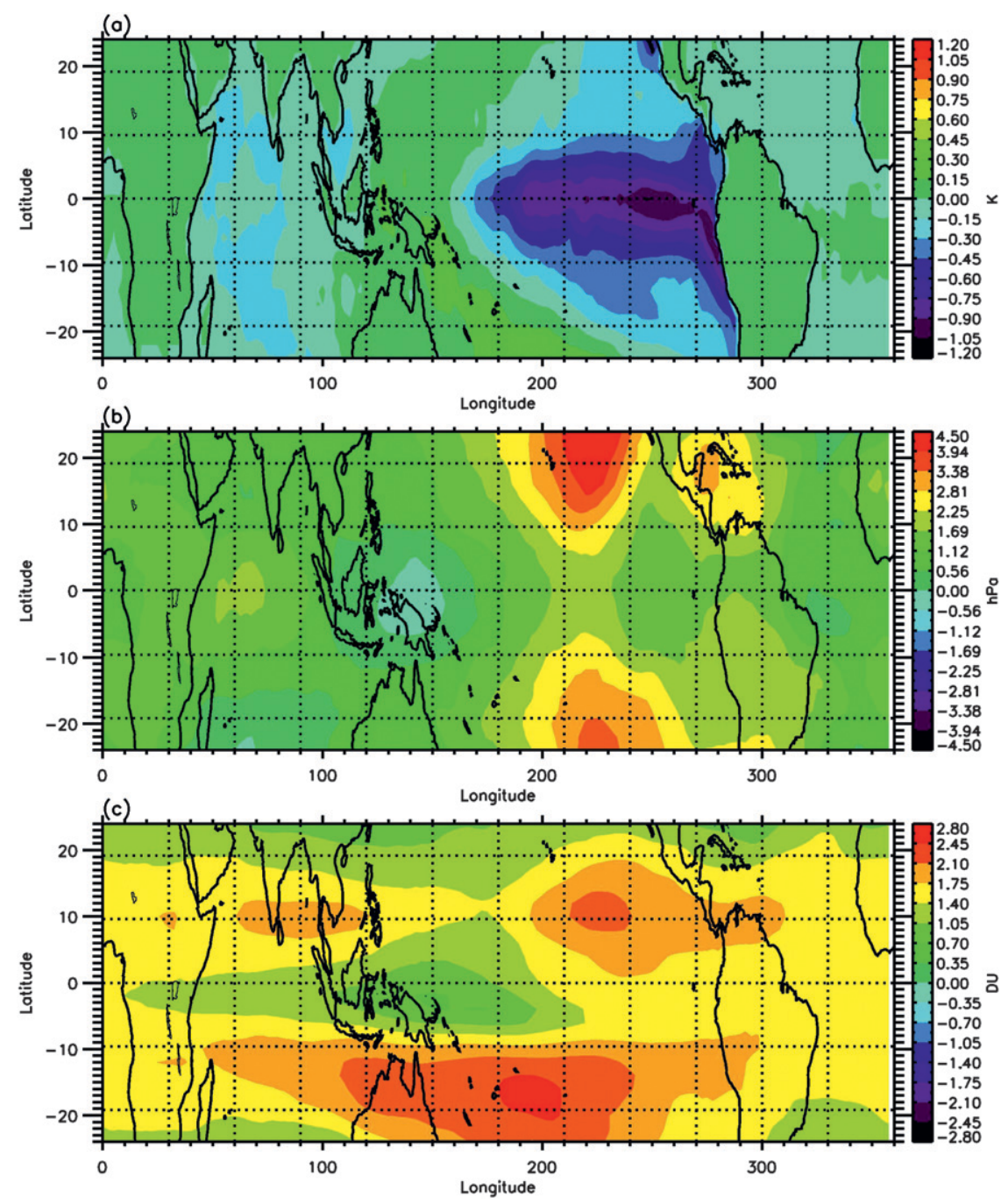

FIG. 3. (a) The spatial pattern of the first mode for GEOS CCM SST in the tropics. The first mode explains $46.9 \%$ of the total variance. (b) The spatial pattern of the first mode for GEOS CCM $P_{T}$ in the tropics. The first mode explains $33.9 \%$ of the total variance. (c) The spatial pattern of the first mode for GEOS CCM $\Omega_{S}$ in the tropics. The first mode explains $63.8 \%$ of the total variance.

associated with the ENSO is reasonably captured by the GEOS CCM.

One important aspect of the spatial pattern of the $P_{T}$ anomaly is that it has the same sign everywhere except for a confined region centered over the equator to the north of Indonesia (Fig. 3b). This contrasts with the existence of positive and negative anomalies in the SST pattern. This means that almost the entire tropical tropopause is displaced upward (to lower pressure) in El Niño events, with a discernable signal in the zonal mean. A similar result holds for the $\Omega_{S}$ pattern (Fig. 3c), in that substantial zonal anomalies are superimposed on a monotonic signal, which implies the forcing of the Brewer-Dobson circulation (Garcia-Herrera et al.
2006) in addition to the forcing by tropical convection during El Niño events. Note that the ENSO signal dominates the variability in $\Omega_{S}$ because irradiance changes associated with the solar cycle were not included in the simulation and because this version of GEOS $\mathrm{CCM}$ does not simulate the QBO. The pattern is very similar to the ENSO spatial pattern in the TOMS total column ozone data found by Camp et al. (2003, see their Fig. 5), although there are some differences in the Southern Hemisphere. The differences in the total column ozone in the Southern Hemisphere might arise because that the model has an unrealistic representation of the Antarctic polar vortex, with too much interannual variability compared to observations (Pawson et al. 

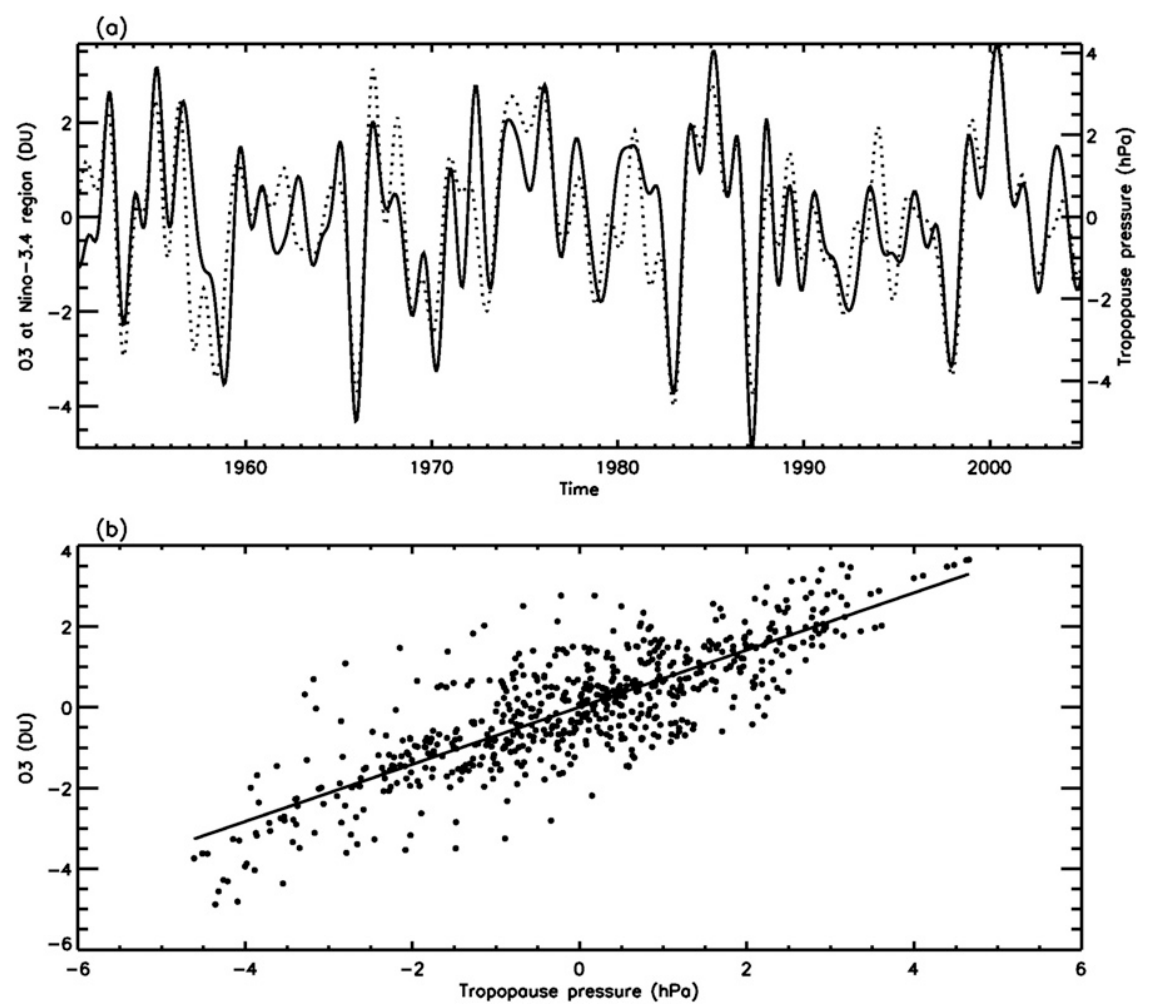

FIG. 4. (a) First mode of GEOS CCM $\Omega_{S}$ averaged over the Niño-3.4 region (solid line) and first mode of GEOS CCM $P_{T}$ averaged at the Niño-3.4 region (dotted line). Correlation coefficient between the two time series is 0.82 ( $0.1 \%$ significance level). (b) Scatterplot for GEOS $\mathrm{CCM} \Omega_{S}$ and $P_{T}$. Both data are averaged over the Niño-3.4 region. The solid line is the linear fit of the data.

2008). The fourth mode of TOMS total column ozone obtained by Camp et al. (2003) is not entirely explained by the ENSO signal. There are other weak signals (e.g., decadal signal) present in the fourth mode of TOMS ozone (Camp et al. 2003), while there is no decadal signal in the results from model ozone. This might explain some discrepancies between model and observations. The spatial pattern of the ENSO signal in the model total column ozone is also consistent with the second mode (mature stages of the El Niño) for the total column ozone from Kayano (1997, see her Fig. 1). The value is relatively low in the western Pacific and relatively high in the eastern Pacific.

A broadly consistent picture arises from the leading anomalies, with (in El Niño events) an eastward migration of warm SST anomalies that enhance convection over the eastern Pacific where the tropopause rises and $\Omega_{S}$ decreases. This decrease in total column ozone is consistent with the changes of the tropopause. It is also consistent with a faster vertical flow through the ozone source region in the tropical stratosphere, which tends to reduce the total column ozone. During El Niño, vertical propagation of Rossby wave and divergence of
Eliassen-Palm flux are enhanced, accelerating the Brewer-Dobson circulation (Garcia-Herrera et al. 2006). Thus, the vertical flow in the tropical stratosphere is enhanced. It leads to a decrease in total column ozone in the tropical region and an increase of total column ozone in the middle to high latitudes.

Since there is strong correspondence between total column ozone and tropopause pressure, we regress the first mode of the total column ozone on the first mode of the tropopause pressure. The mean value for the first mode of the total column ozone in the Niño-3.4 region $\left(5^{\circ} \mathrm{N}-5^{\circ} \mathrm{S}, 120^{\circ}-170^{\circ} \mathrm{W}\right)$ is plotted against the mean value for the first mode of the tropopause pressure in Fig. 4a. The Niño-3.4 region is chosen for its proximity to the Pacific warm pool and main centers of convection (Trenberth 1997). When the Niño-3.4 region SST anomaly is larger than $+0.4^{\circ} \mathrm{C}$, it corresponds to an El Niño event. The time series of total column ozone and tropopause pressure averaged in the Niño-3.4 region correlate well. The correlation coefficient is 0.82 and it is significant at the $0.1 \%$ level. The scatterplot for the two time series is shown in Fig. 4b. The regression coefficient between the total column ozone and tropopause pressure 
TABLE 2. Geographical locations and record lengths of $\Omega_{S}$ time series observed at different stations.

\begin{tabular}{lcrc}
\hline \hline \multicolumn{1}{c}{ Station } & Lat $\left(^{\circ}\right)$ & Lon $\left(^{\circ}\right)$ & Time series \\
\hline Potsdam & 52.36 & 13.08 & $1964-2003$ \\
Belsk & 51.84 & 20.79 & $1963-2003$ \\
Hradec & 50.18 & 15.83 & $1961-2005$ \\
Hohenpeissenberg & 47.8 & 11.02 & $1967-2005$ \\
Arosa & 46.7 & 9.68 & $1926-2005$ \\
Toronto & 43.78 & -79.47 & $1960-2003$ \\
Sapporo & 43.05 & 141.33 & $1958-2005$ \\
Nashville & 36.25 & -86.57 & $1962-2004$ \\
\hline
\end{tabular}

is 0.71 Dobson units (DU) $\mathrm{hPa}^{-1}$. Assuming that the tropopause height is $10.5 \mathrm{~km}$ and scale height is $7 \mathrm{~km}$, the regression coefficient translates $-15.5 \mathrm{DU} \mathrm{km}^{-1}$, which is consistent with the previous results that range from -10 to $-25 \mathrm{DU} \mathrm{km}^{-1}$ (Meetham 1937; Reed 1950; Hoinka et al. 1996; Steinbrecht et al. 1998).

\section{b. The 3.5-yr ozone signal}

As mentioned above, because of the vertical propagation of Rossby wave and divergence of the EliassenPalm flux, ENSO influences the total column ozone not only in the tropical region but also in the middle and high latitudes. Total column ozone data at 21 stations are used to investigate an interesting interannual variability with a period around $3.5 \mathrm{yr}$. These stations are chosen for their relatively long time series (more than $20 \mathrm{yr}$ ). Spectral power analysis is applied to the deseasonalized and detrended total column ozone at all stations. In the 21 stations, only 8 stations display a significant 3.5-yr signal. The other stations have signals at 4-5 or 2-3 yr. There is also no preference of the locations for stations that have the 3.5-yr signal in the total column ozone. The eight stations with a significant 3.5-yr signal are Potsdam, Belsk, Hradec, Hohenpeissenberg, Arosa, Toronto, Sapporo, and Nashville. The geographical locations and record lengths of the eight stations are listed in Table 2. The power spectra and statistical significances of the peaks are shown in Fig. 5 for the eight stations. Dotted lines are the red noise spectra. Dasheddotted lines and dashed lines show $10 \%$ and 5\% significance levels, respectively. In Fig. 5a, there are about five significant spectral peaks ( $10 \%$ significance level) in the low-frequency regions: the residual annual cycle, QBOannual beat, QBO, 3.5-yr signal, and a decadal oscillation. Since the mechanisms for the QBO-annual beat, QBO, and the decadal oscillation are well known (Tung and Yang 1994a,b; Jiang et al. 2005; Baldwin et al. 2001; Soukharev and Hood 2006), we only focus on the 3.5-yr signal in this paper. Among the eight stations, there are significant peaks in the range of 3-4 yr. The power spectra of Potsdam (Fig. 5a), Hohenpeissenberg
(Fig. 5d), and Sapporo (Fig. 5g) lie within the 5\%-10\% range of significance. The significance of the 3.5-yr signals in the other five stations-Belsk (Fig. 5b), Hradec (Fig. 5c), Arosa (Fig. 5e), Toronto (Fig. 5f), and Nashville (Fig. 5h) - are within the 5\% level.

To verify the mechanism for the 3.5-yr cycle and explain the results presented above, we investigated the total column ozone signal in the GEOS CCM. Spectral analysis of the simulated total column ozone (Fig. 6) reveals statistically significant 3.5-yr signals at the eight stations. The significance levels are within $5 \%-10 \%$ for the total column ozone at Potsdam, Belsk, Hradec, Hohenpeissenberg, Arosa, and Sapporo (Figs. 6a-e,g), while at Toronto and Nashville (Figs. 6f,h), the significance levels are better than $5 \%$.

Because the GEOS CCM simulation is forced by observed SST and sea ice distributions, its atmosphere does represent variability related to these forcings at the boundary, including ENSO events. The absence of both the QBO and solar cycle in the model means that total column ozone variations related to these phenomena are not captured. Since the 3.5-yr signal isolated in total column ozone observations is captured at a significant level in the GEOS CCM, this suggests that this signal originates from the ENSO signal in SST forcing rather than from other forced variations in stratospheric ozone, although on the basis of this analysis we cannot preclude the possibility that internal (unforced) dynamics cause this signal.

\section{Conclusions}

In this paper, we have studied the ENSO signal in the tropical total column ozone and tropical tropopause pressure in the GEOS CCM from January 1951 to December 2004. The first modes in the model tropical total column ozone and tropopause pressure capture $63.8 \%$ and $33.9 \%$ of the total variances, respectively. The PC1 for the first modes in the model total column ozone and tropopause pressure correlate well with the low-pass filtered SOI index and leading PC time series for the SST. The spatial pattern of the first mode for the model total column ozone is similar to the ENSO signal in the TOMS total column ozone, although there are some discrepancies for the total column ozone in the Southern Hemisphere. The regression coefficient between the model total column ozone and the model tropopause pressure is consistent with that found from observations.

In the middle latitudes, we applied spectral analysis to the observed monthly mean total column ozone data and find the 3.5-yr signal, within the $10 \%$ significance level, at eight stations. The 3.5-yr signal is also found in the GEOS CCM model total column ozone. Since GEOS CCM does have a realistic ENSO signal and does not have 

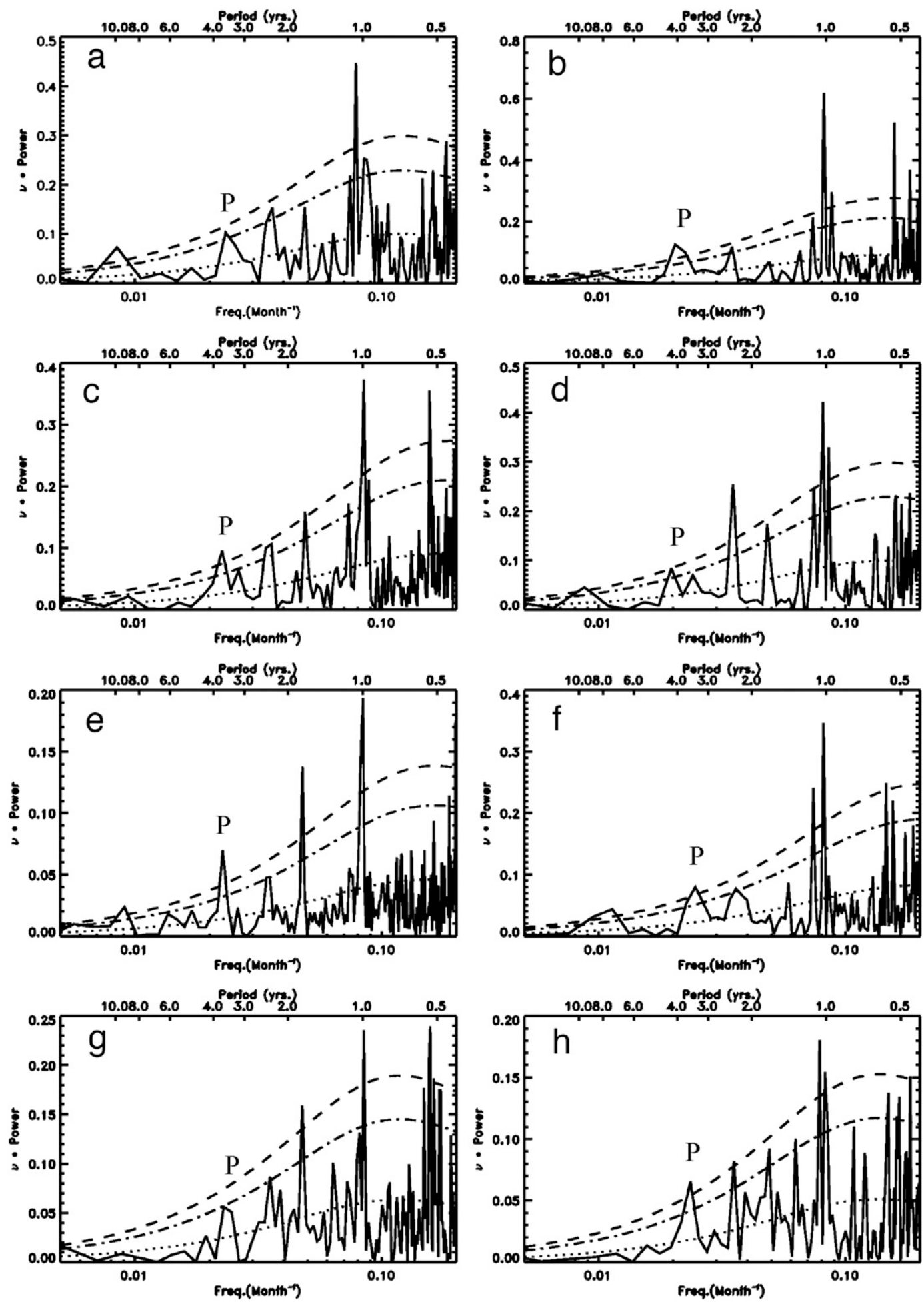

FIG. 5. Power spectra of the deseasonalized and detrended $\Omega_{S}$ observed at different stations: (a) Potsdam, (b) Belsk, (c) Hradec, (d) Hohenpeissenberg, (e) Arosa, (f) Toronto, (g) Sapporo, and (h) Nashville. Dotted lines are the mean red noise spectra. Dashed-dotted lines and dashed lines are 10\% and 5\% significance levels, respectively; $\mathrm{P}$ denotes the 3.5-yr signal. 

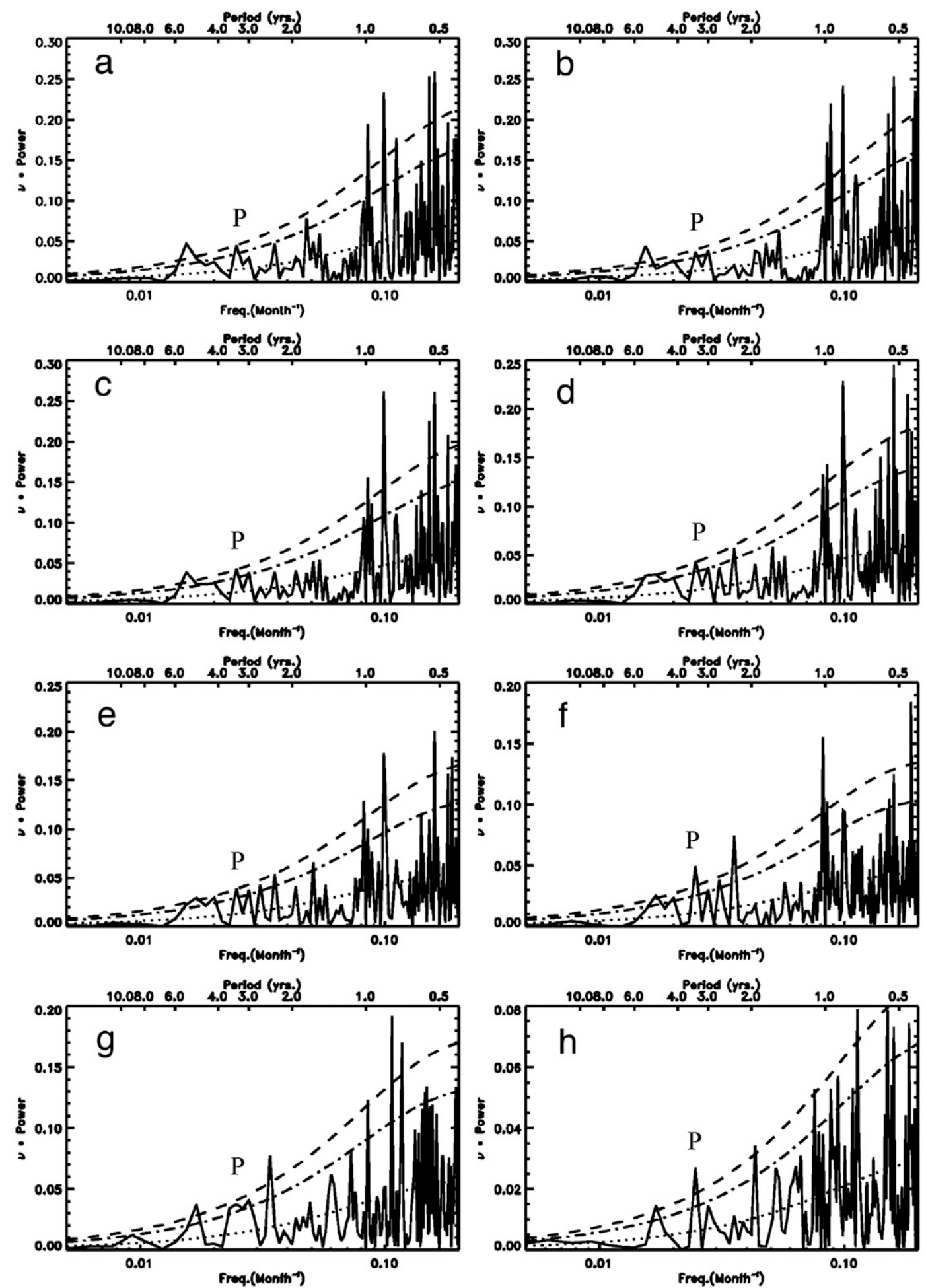

FIG. 6. Power spectra of the deseasonalized and detrended GEOS CCM $\Omega_{S}$ data sampled at the same locations as those in Fig. 5. Dotted lines are the mean red noise spectra. Dashed-dotted lines and dashed lines are $10 \%$ and $5 \%$ significance levels, respectively; P denotes the 3.5-yr signal. 
a QBO or a solar cycle, the results suggest that the 3.5-yr signal in total column ozone is related to the ENSO signal. The linkage between 3.5-yr ozone signal and surface ENSO needs to be investigated in more detail in the future, for example by using controlled model experiments in which the ENSO forcing is removed.

Acknowledgments. We thank Bernhard Rappenglueck, Barry Lefer, Mimi Gerstell, and three anonymous reviewers for useful inputs and helpful comments. We thank the World Ozone and Ultraviolet Radiation Data Centre for providing the ozone observation data. Dr. Tian's research was carried out at the Jet Propulsion Laboratory, California Institute of Technology, under a contract with the National Aeronautics and Space Administration.

\section{REFERENCES}

Baldwin, M. P., and Coauthors, 2001: The quasi-biennial oscillation. Rev. Geophys., 39, 179-229.

Bojkov, R. D., 1987: The 1983 and 1985 anomalies in ozone distribution in perspective. Mon. Wea. Rev., 115, 2187-2201.

Cagnazzo, C., and Coauthors, 2009: Northern winter stratospheric temperature and ozone responses to ENSO inferred from an ensemble of chemistry climate models. Atmos. Chem. Phys., 9, 8935-8948.

Camp, C. D., M. S. Roulston, and Y. L. Yung, 2003: Temporal and spatial patterns of the interannual variability of total ozone in the tropics. J. Geophys. Res., 108, 4643, doi:10.1029/ 2001JD001504.

Chandra, S., J. R. Ziemke, W. Min, and W. G. Read, 1998: Effects of 1997-1998 El Niño on tropospheric ozone and water vapor. Geophys. Res. Lett., 25, 3867-3870.

Douglass, A. R., M. R. Schoeberl, and R. B. Rood, 2003: Evaluation of transport in the lower tropical stratosphere in a global chemistry and transport model. J. Geophys. Res., 108, 4259, doi:10.1029/2002JD002696.

Dunteman, G. H., 1989: Principal Components Analysis. International Education and Professional Publisher, 98 pp.

Eyring, V., and Coauthors, 2006: Assessment of temperature, trace species, and ozone in chemistry-climate model simulations of the recent past. J. Geophys. Res., 111, D22308, doi:10.1029/ 2006JD007327.

Free, M., and D. J. Seidel, 2009: Observed El Niño-Southern Oscillation temperature signal in the stratosphere. J. Geophys. Res., 114, D23108, doi:10.1029/2009JD012420.

Gage, K. S., and G. C. Reid, 1987: Longitudinal variations in tropical tropopause properties in relation to tropical convection and El Niño-Southern Oscillation events. J. Geophys. Res., 92, 14 197-14 203.

Garcia-Herrera, R., N. Calvo, R. R. Garcia, and M. A. Giorgetta, 2006: Propagation of ENSO temperature signals into the middle atmosphere: A comparison of two general circulation models and ERA-40 reanalysis data. J. Geophys. Res., 111, D06101, doi:10.1029/2005JD006061.

Gettelman, A., W. J. Randel, S. Massie, F. Wu, W. G. Read, and J. M. Russell III, 2001: El Niño as a natural experiment for studying the tropical tropopause region. J. Climate, 14, 3375-3392.

Gilman, D. L., F. J. Fuglister, and J. M. Mitchell, 1963: On the power spectrum of "red noise." J. Atmos. Sci., 20, 182-184.
Hasebe, F., 1993: Dynamical response of the tropical total ozone to sea surface temperature changes. J. Atmos. Sci., 50, 345-356.

Hoinka, K. P., H. Claude, and U. Kohler, 1996: On the correlation between tropopause pressure and ozone above central Europe. Geophys. Res. Lett., 23, 1753-1756.

Hood, L. L., B. E. Soukharev, and J. P. McCormack, 2010: Decadal variability of the tropical stratosphere: Secondary influence of the El Niño-Southern Oscillation. J. Geophys. Res., 115, D11113, doi:10.1029/2009JD012291.

Horinouchi, T., and Coauthors, 2003: Tropical cumulus convection and upward propagating waves in middle atmospheric GCMs. J. Atmos. Sci., 60, 2765-2782.

Jiang, X., D. B. A. Jones, R. Shia, D. E. Waliser, and Y. L. Yung, 2005: Spatial patterns and mechanisms of the quasi-biennial oscillation-annual beat of ozone. J. Geophys. Res., 110, D23308, doi:10.1029/2005JD006055.

_ , Q. Li, M. Liang, R. L. Shia, M. T. Chahine, E. T. Olsen, L. L. Chen, and Y. L. Yung, 2008a: Simulation of upper troposphere $\mathrm{CO}_{2}$ from chemistry and transport models. Global Biogeochem. Cycles, 22, GB4025, doi:10.1029/2007GB003049.

_ - S. Pawson, C. D. Camp, J. E. Nielsen, R.-L. Shia, T. Liao, V. Limpasuvan, and Y. L. Yung, 2008b: Interannual variability and trends in extratropical ozone. Part I: Northern Hemisphere. J. Atmos. Sci., 65, 3013-3029.

Kayano, M. T., 1997: Principal modes of the total ozone on the Southern Oscillation timescale and related temperature variations. J. Geophys. Res., 102, 25 797-25 806.

Kiladis, G. N., K. H. Straub, G. C. Reid, and K. S. Gage, 2001: Aspects of interannual and intraseasonal variability of the tropopause and lower stratosphere. Quart. J. Roy. Meteor. Soc., 127, 1961-1983.

Kita, K., M. Fujiwara, and S. Kawakami, 2000: Total ozone increase associated with forest fires over the Indonesian region and its relation to the El Niño-Southern oscillation. Atmos. Environ., 34, 2681-2690.

Meetham, A. R., 1937: The correlation of the amount of ozone with other characteristics of the atmosphere. Quart. J. Roy. Meteor. Soc., 63, 289-307.

Pawson, S., R. S. Stolarski, A. R. Douglass, P. A. Newman, J. E. Nielsen, S. M. Frith, and M. L. Gupta, 2008: Goddard Earth Observing System chemistry-climate model simulations of stratospheric ozone-temperature coupling between 1950 and 2005. J. Geophys. Res., 113, D12103, doi:10.1029/ 2007JD009511

Preisendorfer, R. W., 1988: Principal Component Analysis in Meteorology and Oceanography. Developments in Atmospheric Science Series, Vol. 17, Elsevier, 425 pp.

Press, W., S. Teukolsky, W. Vetterling, and B. Flannery, 1992: Numerical Recipes in Fortran 77: The Art of Scientific Computing. Cambridge University Press, $933 \mathrm{pp}$.

Rayner, N. A., D. E. Parker, E. B. Horton, C. K. Folland, L. V. Alexander, D. P. Rowell, E. C. Kent, and A. Kaplan, 2003: Global analyses of sea surface temperature, sea ice, and night marine air temperature since the late nineteenth century. J. Geophys. Res., 108, 4407, doi:10.1029/2002JD002670.

Reed, R. J., 1950: The role of vertical motions in ozone-weather relationships. J. Meteor., 7, 263-267.

Schubert, S. D., and M. J. Munteanu, 1988: An analysis of tropopause pressure and total ozone correlations. Mon. Wea. Rev., 116, 569-582.

Shiotani, M., 1992: Annual, quasi-biennial, and El Niño-Southern Oscillation (ENSO) time-scale variations in equatorial total ozone. J. Geophys. Res., 97, 7625-7633. 
Soukharev, B. E., and L. L. Hood, 2006: Solar cycle variation of stratospheric ozone: Multiple regression analysis of long-term satellite data sets and comparisons with models. J. Geophys. Res., 111, D20314, doi:10.1029/2006JD007107.

Steinbrecht, W., H. Claude, U. Kohler, and K. P. Hoinka, 1998: Correlations between tropopause height and total ozone: Implications for long-term changes. J. Geophys. Res., 103, 19 183-19 192.

Stolarski, R. S., A. R. Douglass, S. E. Steenrod, and S. Pawson, 2006: Trends in stratospheric ozone: Lessons learned from a 3D chemical transport model. J. Atmos. Sci., 63, 1028-1041.

Sturman, A. P., and N. Tapper, 1996: The Weather and Climate of Australia and New Zealand. Oxford University Press, 475 pp.

Thompson, A. M., and R. D. Hudson, 1999: Tropical tropospheric ozone (TTO) maps from Nimbus 7 and Earth Probe TOMS by the modified-residual method: Evaluation with sondes, ENSO signals, and trends from Atlantic regional time series. J. Geophys. Res., 104, 26 961-26975.

Tian, B., Y. L. Yung, D. E. Waliser, T. Tyranowski, L. Kuai, E. J. Fetzer, and F. W. Irion, 2007: Intraseasonal variations of the tropical total ozone and their connection to the MaddenJulian oscillation. Geophys. Res. Lett., 34, L08704, doi:10.1029/ 2007GL029451.
Trenberth, K. E., 1997: The definition of El Niño. Bull. Amer. Meteor. Soc., 78, 2771-2777.

, and D. J. Shea, 1987: On the evolution of the Southern Oscillation event. Mon. Wea. Rev., 115, 3078-3096.

, G. Branstator, D. Karoly, A. Kumar, N.-C. Lau, and C. Ropelewski, 1998: Progress during TOGA in understanding and modeling global teleconnections associated with tropical sea surface temperatures. J. Geophys. Res., 103, 14 291-14 324.

_ J. M. Caron, D. P. Stepaniak, and S. Worley, 2002: Evolution of El Niño-Southern Oscillation and global atmospheric surface temperatures. J. Geophys. Res., 107, 4065, doi:10.1029/ 2000JD000298.

Tung, K. K., and H. Yang, 1994a: Global QBO in circulation and ozone. Part I: Reexamination of observational evidence. J. Atmos. Sci., 51, 2699-2707.

— Part II: A simple mechanistic model. J. Atmos. Sci., 51, 2708-2721.

Zerefos, C. S., A. F. Bais, I. C. Ziomas, and R. D. Bojkov, 1992: On the relative importance of quasi-biennal oscillation and El Niño/Southern Oscillation in the revised Dobson total ozone records. J. Geophys. Res., 97, 10 135-10 144. 